\title{
El Método Fenomenológico Crítico de Investigación con Base en el Pensamiento de Merleau-Ponty
}

\author{
The Critical Phenomenological Research Methodology Based on \\ Merleau-Ponty's Philosophy
}

\author{
Dilcio Dantas Guedes* \\ Universidade Estadual do Piauí, Brasil
}

\author{
Virginia Moreira** \\ Universidade de Fortaleza , Brasil
}

(Rec: 3 de julio de 2009 Acep: 18 de noviembre 2009)

\begin{abstract}
Resumen
Presenta la aplicación del método fenomenológico crítico de investigación, con base en la filosofía de MerleauPonty. Describe su fenomenología, para discutir algunos presupuestos de esta propuesta metodológica, así como las implicaciones de su concepción de hombre mundano, que hacen que ésta sea una fenomenología crítica. Presenta a través del ejemplo de la investigación de la vivencia del estigma en mujeres abandonadas por sus maridos en Tianguá - CE - Brasil, como el investigador fenomenológico crítico conduce las intervenciones fenomenológicas en la entrevista y cómo analiza los contenidos emergentes de forma crítica, asumiéndose como investigador mundano que posee una hipótesis cómo desconfianza sobre lo que investiga, y que debe "salir de los paréntesis".

Palabras clave: Pesquisa fenomenológica crítica, Merleau-Ponty, método fenomenológico.
\end{abstract}

\begin{abstract}
This article presents the application of the critical phenomenological research methodology, based on Merleau-Ponty's philosophy. It describes his phenomenology, and it discusses some fundamental presupposes, as well as the implications of its conception of worldly man, which make this methodology a critical phenomenology. It shows an example of the research of the lived experience of stigma in women from being abandoned by their husbands in Tianguá - CE - Brazil, how the critical phenomenological researcher conducts the phenomenological interventions in the interview, and how he analyses the emergent contents critically, assuming himself as a worldly researcher, whom has an hypothesis as a misgiving about what one is looking for and that should go out from the brackets.
\end{abstract}

Keywords: Critical phenomenological research, Merleau-Ponty, phenomenological method.

\footnotetext{
Correspondencia: 103, Rue Haxo, 75020 Paris - France

E-mail: dilcio@gmail.com

** SP. Profesora titular del Magíster en Psicología de la Universidade de Fortaleza.

Correspondencia a: Mestrado em Psicologia - Universidade de Fortaleza. Av. Washington Soares, 1321- 60811-341 - Fortaleza, CE - Brasil

E-mail: virginiamoreira@unifor.br
} 


\section{Introducción}

En este artículo presentamos un ejemplo práctico del método fenomenológico crítico con base en el pensamiento de Merleau-Ponty (Moreira, 2004), aplicado a la investigación sobre las vivencias: la investigación de la experiencia vivida del estigma por mujeres dejadas por los maridos en Tianguá, en el interior de Ceará, en Brasil. Enfatizamos, especialmente, la noción de hombre que este abordaje sostiene, bien como su propuesta de construcción del conocimiento, a fin de encaminar una metodología crítica para el estudio de las vivencias. Finalmente, ejemplificamos aspectos metodológicos de este abordaje de encuesta, que privilegia la profundidad y la variabilidad de los significados producidos. La comprensión de las vivencias parte de la minuciosa descripción de experiencia vivida. Éstas deben articularse a un norte de la investigación, remetiéndose a un conjunto de variables y de hipótesis, mientras sospechas acerca del fenómeno (Moreira, 2004). De la misma forma, enfatizamos el entrenamiento de intervenciones fenomenológicas y el ejercicio de la reducción para que se pueda dar cuenta de los diferentes matices de la vivencia en su campo inter-subjetivo e intra-subjetivo, aunque sepamos que esta delimitación de subjetividades es imposible de completarse, tal como la reducción fenomenológica que nunca se completa (Merleau-Ponty, 1945).

Describiremos, de forma sucinta, inicialmente, la fenomenología de Merleau-Ponty en la cual se pauta esta metodología de investigación. En secuencia la metodología será presentada, explicitando técnicas específicas tales como la descripción y las intervenciones fenomenológicas, ilustradas con ejemplos prácticos de la encuesta sobre la vivencia del estigma de ser dejada por el marido, que muestran el análisis de las vivencias emergentes.

\section{La fenomenología de Merleau-Ponty: El hombre mundano}

La fenomenología, para Merleau-Ponty [1945 (1994)], no es un idealismo transcendental, pues quiere tematizar la existencia, el ser-en-el-mundo. La esencia está en la existencia. Según Abbagnano (1998), estos termos consideran la admisión que los "cuerpos tienen solamente existencia ideal en nuestro espíritu, negando así la existencia real de los propios cuerpos y del mundo" (p. 523). Acentúa, entonces, que el foco de esta existencia es la cosa en sí, para allá y en sí mismo de lo que se es. Así, el interés de Merleau-Ponty está vuelto para un hombre concreto e histórico, luego, multi-facetado, o sea, con múltiples dimensiones. Su propuesta filosófica está implicada a la descripción del real para llegarse a la comprensión de los contornos del fenómeno; dicho de otra forma, a la singularidad del vivido (Moreira, 2004). Su concepción nos indica que el mundo ya está allí y su tentativa primordial es, simplemente, describirlo, pues el rigor de la ciencia está articulado a la experiencia del mundo vivido, siendo este vivido y la inter-subjetividad imbricados en este mundo que se objetiva investigar.

Merleau-Ponty [1945 (1994)] esclarece que la problemática de la fenomenología, en su versión más elaborada, post-husserliana, restaura la tensión dialéctica entre los polos del subjetivismo y objetivismo extremo al incluir la comprensión del hombre en su facticidad. Esta tensión implicaría en una fenomenología que enfatiza la experiencia como elemento primordial para la comprensión del mundo. Tal comprensión del fenómeno ocurriría en la intersección de mis experiencias subjetivas y las experiencias del otro en variados horizontes vivenciales, como el espacio, el tiempo, el cuerpo y la propia inter-subjetividad. Así, el real debería ser descrito, visto que no se puede establecer un análisis en la perspectiva de un sujeto y un objeto, ya que es de una constitución mutua entre sujeto y objeto que se trata.

Estamos hablando de un hombre mundano - una concepción que precede a la reflexión, pues en el mundo es donde él se reconoce y no a través de un hombre interior, circunscrito a procesos encubiertos o a articulaciones meta-interiorizadas. De esta forma, lo que hay de singular y de universal se entrelaza para dar sentido a un hombre histórico y, como tal, en constantes desdoblamientos. El hombre está íntimamente unido a su condición histórica, perpasando por su mutua constitución con el mundo en su realidad intrínseca. Este hombre es, antes mismo de ser reflejado, concreto, como dado de realidad. Por esto, tiene infinitas posibilidades de experiencias, tal como nos recuerda Merleau-Ponty [1945 (1994)]: "El mundo no es lo que yo pienso, sino aquello que yo vivo; estoy abierto al mundo, me comunico indubitablemente con él; pero no le poseo, él es inagotable" (p.14). Es decir, el mundo no está circunscrito a concepciones interiorizadas y el hombre posee una comprensión singular del mundo, moviéndose de forma igualmente singular, pues éste remete a su modo de percibirse y de percibir el otro en el flujo de la existencia. El hombre mundano es ambiguo, lo que amplía su abertura para la producción de significados de su experiencia vivida. Entrelazado en el mundo y prolongamiento de él por el cuerpo, se torna singular por la mutabilidad de su estar-en-el-mundo, de forma múltiple y con contornos variables, constituyéndose en torno de un flujo constante de significados. Con la noción de hombre mundano, las dicotomías (sujeto-objeto, cuerpo-espíritu, interno-externo) son cuestionadas, mientras los "pensamientos de sobrevuelo" desraizarían al hombre de su inherencia al mundo.

\section{La reducción fenomenológica}

La propuesta de la reducción, como estrategia de ir para allá del empírico y de la lógica deductiva, intenta abarcar la emergencia del fenómeno de la ciencia. El primordial en la investigación fenomenológica es la descripción de la 
experiencia vivida. Como la experiencia vivida se constituye en flujo temporal y como de la imbricación del hombre y del mundo, en mutua constitución, el papel de la investigación sería la descripción del campo fenomenológico, pero también la comprensión propia de esta constitución mundana del hombre, como ser-en-el-mundo. Por eso, lanzar mano de la reducción fenomenológica como estrategia frente a la imbricación hombre-mundo constituiría condiciones para vislumbrar el paradojal de esta mutualidad a abrir espacio para comprender las singularidades del campo de experiencias. Para Merleau-Ponty, la reducción fenomenológica es la resolución no de suprimir, pero de poner en suspenso, con que «fuera de acción» todas las afirmaciones espontáneas en que vivimos, no para negarlas, sino para comprenderlas y explicitarlas. Se trata de la búsqueda del significado singular, siempre entrelazado a la universalidad del vivido, una revelación de la existencia o facticidad (Moreira, 2004).

Podemos, entonces, pensar que la fenomenología radicaliza la relación del hombre y del mundo entre sí como flujo constante de producción de sentido, marcadamente histórica e intercorpórea, pues entrelaza varios horizontes vivenciales para darse cuenta de la mutualidad inherente a ellos. Podemos pensar, también, que este método toma conciencia del comprometimiento con la concretad dialetizada por la tensión de polaridades sin síntesis de esta misma relación hombre-mundo.

\section{Los múltiples contornos de la vivencia}

El campo fenoménico parece, en este contexto, presentarse como un conjunto de experiencias que orienta la conducta del sujeto en el mundo y permite la elaboración de un proyecto existencial, a partir del cuerpo. El cuerpo pasa a ser el elemento clave de esa inserción consciente en el mundo, ya que es dotado de un elemento de proyección para la cultura, que a su vez confiere el sentido intercambiable del campo intersubjetivo, el lenguaje. El lenguaje es, desde estos aspectos, un sistema específico de vocabulario y sintaxis que revela la unión del sujeto con el estar-en-elmundo y, por lo tano, expone la condición del ser como hombre en situación. Como tal, este hombre no es libre por completo, visto que está comprometido en el mundo con infinidades de posibles, siendo estas infinitas opciones de existencia que apuntan el carácter singular de cada ser. Dicho de otra manera, cada sujeto se individualiza por el proyecto existencial con el cual se compromete. Esa condición inalienable remete a la ambigüedad, que condiciona el carácter delimitado de la libertad del hombre. Así, el mundo se reconoce por la pluridimensionalidad de la existencia y por la polisemia inagotable frente a un hombre concreto.

Así dicho, reiteramos que entendemos la vivencia de los sujetos-colaboradores de la investigación sobre las vivencias como una construcción, de múltiples dimensiones, fundamentada en la tensión de polaridades concebidas por la concepción de un hombre entrelazado a un mundo concreto, histórico y social, intrínsecamente constituido en éste y con el mundo, manifestados por movimientos constituyentes de sus representaciones de las experiencias en los entrelazamientos de condiciones cognitivas, volitivas y emocionales. De esta forma, la vivencia es entendida como una construcción que el sujeto hace consigo mismo y con los otros, a partir de la inter-relación de las experiencias pre-reflejadas y reflexivas, en un continuo del flujo de la existencia, unida a la facticidad del mundo, tal como se presentaba. Las vivencias son un flujo autónomo de producción de sentido, eminentemente intersubjetivo; por lo tanto, que no se traduce en una verdad absoluta.

Una vez más, llamamos la atención para el hecho de que el énfasis de la propuesta de la investigación crítica merleaupontiana recae en el darse cuenta del significado de la experiencia vivida, a partir de un campo intersubjetivo, articulado a las dimensiones espaciales, temporales, corporales e intersubjetivas de la existencia (Moreira, 1998; 2004). Este proceso de mutuo constitución del hombre y del mundo es revelado por un cogito en situación, que envuelve la conciencia de existir y la conciencia de la existencia del otro en torno de una situación histórica. Merleau-Ponty [1945 (1994)] sostiene este punto de vista, afirmando que, para que nosotros nos apercibamos de esta relación, sería necesario "suspenderla" y admirar lo que se pasa delante del mundo. La única manera de realizar tal movimiento es recusarle nuestra complicidad temporariamente. Pero no en el sentido del abstraerse en una unidad de la conciencia. $\mathrm{Al}$ contrario, en el sentido de alejarse para ver el raro y paradojal de esta imbricación. Esto siempre se da de forma incompleta, porque estamos inextricablemente unidos al mundo y el mundo a nosotros. Merleau-Ponty (1974) enfatiza, así, una proposición filosófica que intenta dar cuenta de las múltiples posibilidades de comprensión del humano a través de una actitud que privilegie "la presencia en el mundo", antes mismo de la reflexión.

\section{El método crítico de investigación con base en la fenomenología de Merleau-Ponty}

Es importante acordarse que cualquier encuesta, sea cualitativa o cuantitativa, o sea, cual sea su tradición, tomará posiciones específicas con respecto, por ejemplo, a la definición del corpus a ser estudiada, del sitio de estudio, del momento histórico en que este ocurre. Así, el investigador, como hombre mundano, enraizado en el mundo, cuando define su metodología no lo hace al acaso. Él tiene hipótesis que darán el camino necesario al proceso investigativo. Aunque exista una resistencia entre investigadores de línea cualitativa que utilizan las terminologías normativas de la investigación en las ciencias naturales y sociales, el darse cuenta de la existencia de estos aspectos de la pesquisa permitiría al investigador lanzar mano de su experiencia de 
reducción fenomenológica para, en secuencia, vislumbrar su imbricamiento ante el fenómeno que investiga. Antes de todo, el investigador no es ingenuo, ni alienado de aquello que le inquieta y le impele a pesquisar. Tal postura posibilitaría al investigador dejar iluminarse y percibir tal iluminación del fenómeno en sus múltiples facetas, delante de la polisemia engendrada y mantenida por la "buena dialéctica", como propone Merleau-Ponty [1945 (1994)].

Así, la clareza acerca de las variables que envuelven la problemática estudiada y las hipótesis que la configuran, además de dar un norte a la postura de abertura para una dialéctica sin síntesis, implican el investigador en la condición de intersubjetividad, evidencia de su "embotellamiento congénito", como diría Merleau-Ponty [1945 (1994)]. En este caso, las hipótesis son sospechas, pero dejan aperturas para que se vislumbre el significado de las experiencias, que nunca será absoluto.

\section{La descripción}

Todo el proceso de la investigación es ampliamente viabilizado cuando la descripción fenomenológica es privilegiada. La descripción del fenómeno es la senda mayor para tener acceso al campo fenoménico del sujetocolaborador. Justamente de ahí surge la idea de utilizarse, en esta metodología de pesquisa, un sujeto colaborador que tenga vivido la experiencia: se presupone que existe una relación dialógica constituida por el interés en aprender, con el otro, el significado del fenómeno en cuestión. El científico quiere aprender con el sujeto-colaborador, que vivió o está viviendo la experiencia que el investigador quiere estudiar. Esta perspectiva abre espacio para que los protagonistas de la pesquisa (enfatizamos: investigador y sujeto colaborador) expongan sus impresiones y sentimientos, articulándolos en una "habla terapéutica", en el caso, engendrada por el científico. Aquí nos utilizamos de la perspectiva de un encuentro fundado en la producción de un flujo interpersonal de producción de sentido, tal cual una postura fenomenológica clínica defendida por Amatuzzi (1989). Obviamente que no se trata de un encuentro psicoterapéutico, y, por eso mismo, se debe resguardar el sujeto-colaborador acordándole que aquél encuentro es circunstancial, tendrá un término y no objetiva, a priori, una mudanza terapéutica.

\section{La intervención fenomenológica}

Los efectos intersubjetivos, articulados entre la descripción y la reducción, remeten a modos de intervención. Entre ellos, tenemos el habla auténtica, como unfeedback o habla movilizadora, que permite el tomar conciencia de sentidos, por un proceso de awareness -un tipo de concientización vivencial- y, sobre todo, una reelaboración acerca de una gestalt ya establecida. El habla auténtico es facilitador para la emergencia del sentido porque es un habla genuino, primario, el habla que "sale desde adentro". Ver y oír fenomenológicamente pueden también ser posturas de intervención del investigador. A través de estas intervenciones, se desdoblarían espacios para la posibilidad de percibir el otro de forma plena y "ver el invisible", más allá del verbal (Moreira, Sabóia, Beco \& Soraes, 1995).

De ahí la importancia de la total participación del científico en todas las fases de la investigación, desde la problematización hasta la fase del análisis, tanto por cuestiones metodológicas exigidas por la postura fenomenológica como por el "embotellamiento" del investigador en el mundo compartido con el sujeto-colaborador. Esa dimensión de intersección es la marca más evidente de este tipo de encuesta, a la luz del método de Merleau-Ponty (1998; 2001; 2004).

Las técnicas de escucha activa también forman parte del contexto de facilitación del flujo de producción de sentido. Ellas pueden ser respuestas de elucidación -aclaración sobre el hecho descrito, por la vía de la síntesis deducida sobre aquello que fue dicho, a fin de confirmación o refutación de la comprensión expuesta; de reiteración -señalando elementos relevantes en el habla del colaborador o reproduciendo sus últimas palabras a fin de que se promueva una continuación del flujo discursivo de reflexión del sentimiento -como comprensión de los elementos emocionales envueltos en la descripción del hecho, favorecido por el envolvimiento existencial y afirmando el vivido del colaborador; de confrontación -al exponer contradicciones en el flujo- discursos o incongruencia entre la producción descriptiva y sus componentes emocionales y la postura corporal o reacciones fisiológicas externalizadas (por ejemplo, ruborización, temor, movimientos de los miembros, etc.) entre otras modalidades (Benjamin, 2002; Rogers \& Kinget, 1997).

Así, para llegar al mundo vivido del sujeto a través de la intervención fenomenológica, el científico puede lanzar mano de dos ratos: el envolvimiento existencial y el alejamiento reflexivo. De acuerdo con la tradición de la investigación fenomenológica empírica (Forghieri, 1989 y 1993; Amatuzzi, 1990 y 1994), en aquél se pone en suspenso cualquier conocimiento adquirido sobre el fenómeno para inserirme en un flujo de experiencias de la vivencia descrita, en la intento de aproximarse lo más genuinamente posible la versión particular del sujeto, en una actitud pre-reflexiva y de afirmación del vivido. En éste se busca distanciarse de la vivencia para enunciarla, describiendo su sentido a partir de la auto-escucha del pesquisidor para exponer su consideración comprensiva del fenómeno como acción desveladora de la afirmación vivencial (Guedes \& Andrade, 1999; Guedes, 2002). Se asume, de esta manera, la idea de que el acceso al vivido se da en una relación viva, que se transforma. Su resultado es más descriptivo-comprensivo que explicativo - lo que, en nuestra propuesta, no significa 
buscar una unidad del significado o síntesis vivencial de la experiencia.

\section{La investigación de la vivencia: un ejemplo}

Adelante exponemos trechos que ejemplifican las transcripciones y el análisis de encuestas de un estudio sobre la vivencia de rompimiento de relación amorosa. Son de mujeres que vivían en Tianguá, una pequeña ciudad al interior de Ceará - Brasil, y que fueron dejadas por sus maridos. En este estudio, sospechábamos que las mujeres vivenciaron el rompimiento como una des-estructuración de su vida personal y emocional, involucrada por la vergüenza y sentimiento de incompetencia frente al papel de cónyuge. Sospechábamos, además, que estas mujeres eran estigmatizadas por la falencia de su papel de esposa y que reaccionaban evitando contactos sociales y haciéndose resistentes a nuevas relaciones amorosas, a causa de la vivencia del estigma. Es decir, éstas eran nuestras hipótesis.

Ejemplos de intervenciones fenomenológicas

La encuesta que sigue fue hecha con una mujer, 33 años, cuyo nivel de escolaridad era primario, separada hace 2 años, con un hijo. Las intervenciones fenomenológicas realizadas por el investigador son precedidas de la letra "I". Para mantener el calor afectivo de las expresiones de esta mujer, mantuvimos el formato de su discurso original, bruto:

I(1): Estoy investigando sobre rompimiento de las relaciones amorosas y me gustaría su ayuda para comprender este tema....

E: ¡Vale! ¿Es para contar porque me separé?

I(2): Cuénteme, ¿cómo fue para Usted esta separación?

E: En el comienzo, fue horrible por qué yo creía que él, mi marido, iba a volver... él ya peleaba mucho y no estaba entendiéndose muy bien... yo sabía que él iba para Ipú [ciudad cercana a Tianguá] y encontraba otras mujeres allá porque me decían, y toda la vida que yo le llamaba para conversar era una pelea... y pelea con pelea fue acabándose como acabó... incluso él mismo salió de casa algunas veces, pero siempre volvía... siempre que necesitaba alguien para darle la comida o lavar sus ropas él volvía...

I(3): Él volvía para usted servirle comida y ropas limpias...

E: Sí, eso es... cuando bebía era que él me procuraba, ¿sí? Pero yo nunca fui mucho de eso...

I(4): ¿Así cómo?:

E: Nunca me gustó mucho la manera de él, no, ¿¿sí? Él era mucho estúpido, entonces yo ni sentí su falta...

I(5): Usted está diciéndome que no le gustaba tener relaciones sexuales con él, ¿es eso?
E: (se ríe) Sí, eso es... él era todo estúpido, ¿sabe? A veces lo que sentía era miedo... pero era la mujer de él, ¿vale? No me casé con él, ¿pues sí? Entonces...

I(6): Entonces...

E: Entonces tendría que cumplir con mis obligaciones de mujer...

I(7): Y, ¿cómo Usted se sintió cuando él rompió el matrimonio?

E: Fue malo, ipues sí! Porque todo el mundo acaba comentando, aun más porque él resolvió dejar la casa... hoy él vive con un hermano, pero él, como es camionero, vive viajando y yo no lo veo... ni quiero verlo... a veces yo sé que él sale por ahí... lo malo también es que yo sé que las personas vienen a hablar de él y acaba llegando en mis oídos ¿sabe? Y yo me quedo con una vergüenza ¿sabe? Las personas creen que yo soy una pobrecita, abandonada... como si yo no tuviera ningún valor para él... o las personas les da pena, vienen a saber si estoy necesitando alguna cosa, pero ya hace mucho tiempo, y yo creo es que si él volviera yo ahora mismo lo dejaría, porque él está mayor y ¿Quién iba a cuidar de él? Yo me quedo pensando en la vejez de él, ¿sabe?

I(8): Tenía entendido que no querría verle.

E: Yo lo dije, pero al fin y al cabo me da pena él, porque era yo que sabía de las cosas de él... yo sólo pienso en su vejez, porque él ya tiene 63 años ¿sabe? Cuando me casé yo tenía 16 años y él $46 .$. yo huí para casarme... porque él estaba separado de otra mujer...

I(9): Parece que Usted está acordándose de cuando ustedes se casaron y ahora habla que se preocupa por la vejez de él...

E: Y la mía también, ¿sí? Porque yo sólo tuve un hombre en la vida... ¿Quién va a querer casarse con una mujer como yo, que sólo sabe las cosas de casa, acostumbrada con aquel hombre?

I(10): Debe haber sido difícil para Usted esta separación... es como si tuviese que re-empezar.

E: Es por eso que yo digo, si él quisiese volver, aunque tuviese sus putas sería mejor... pero se quedaba como antes... porque es mucha vergüenza, ¿sabe? Me parece incluso que fuera enferma, que no supe mantener el marido, y son 17 años, ¿sabe? ¿Y ahora? Yo no hablo a las personas eso ¿sabe? Van a decir que estoy loca por querer un hombre así... pero yo me casé con él por amor, ¿sabe? Yo dejé la casa de mi madre escondida por él... dejé de estudiar y todo... hoy F, mi hijo, ya está un hombre, de ahí a poco se casa, y yo me quedaré sola, porque yo sé que hijo uno lo cría para el mundo... pero cuando las cosas tienen que ocurrir, ocurren igual, ¿sí?

I(11): Tú crees que tu separación iba a ocurrir igual.

E: [silencio] no era para que ocurrira, pero si Dios creyó que era mejor así... 
Evidentemente que no existe una regla, o "un único contorno", para que una entrevista de investigación fenomenológica sea facilitada. En líneas generales, lo importante en esta perspectiva de pesquisa es que el contenido sea exhaustivamente descrito, intentándose aproximar a las variadas dimensiones vivenciales de la experiencia. Para tanto, las técnicas de intervención fenomenológica (Moreira, 1998 y 2001) se tienen mostrado eficientes y viables como procedimiento de colecta y, sobre todo, como postura favorecedora de un clima dialogal menos formal y directivo, como sería en una entrevista tradicional centrada en la problemática a ser investigada. Aunque la entrevista (semi-estructurada) se dé a partir de una pregunta disparadora, ella es abierta y privilegia el "cómo" en lugar del "por qué", así como la polisemia y las ambigüedades presentes en la producción del discurso del otro. No se trata de, por lo tanto, tener acceso a una narrativa elaborada; antes de eso, al modo de ver y pensar íntimos, en constitución y continua reconstitución, que el sujeto realiza sobre su experiencia de acuerdo con el desarrollo temporal en que él representa su vivencia, libre para la producción de una elaboración impar y original.

\section{El significado de las intervenciones fenomenológicas}

Veamos como algunas de esas intervenciones pueden, en terminos prácticos, ser analizadas:

Los movimientos y "saliendo de los paréntesis": visualizando algunos contornos de la vivencia.

A partir del recorte de otro relato, identificamos los movimientos, de acuerdo con los criterios descritos en los pasos. Con fines didácticos, para cada movimiento identificamos con la letra M y su número. Por ejemplo: /M1/, /M2/ etc., para "movimiento 1", "movimiento 2". El movimiento al que nos referimos es un recorte señalado por una idea compleja, una quiebra en la producción textual, una mudanza de contexto semántico. Tales estructuras son, por su vez, indicadas en la producción del habla en su totalidad. Dicho de otra manera, por la quiebra del flujo discursivo generado por una reticencia, o por un suspiro, o mismo por el brollar del lloro. También puede ser demarcado por una mudanza corporal (por ejemplo, mudanza de posición, girar la cara para no mirar al investigador, bajar la cabeza, poner las manos entre las piernas, etc.), incluso poner una expresión racionalizada en el medio de una evocación emocional de la vivencia o una clara negación en continuar a hablar sobre determinado tema. Las posibilidades de movimientos son infinitas, pero pueden ser bien demarcadas si el investigador está atento a las dimensiones de la vivencia y a su autoescucha cuando colecta sus datos.

Se trata de una etapa fundamental en una pesquisa fenomenológica crítica. Por ser una investigación fenomenológica, ella debe tornar posible que todos los fenómenos puedan emerger de forma espontánea. Así, durante la conducción de la entrevista, el entrevistador deberá tener puesto "entre paréntesis" su hipótesis, en cuanto investigador mundano, realizando así la reducción fenomenológica (aun cuando no podamos olvidar que ésta nunca se completa). En este ejemplo, teníamos como hipótesis que estas mujeres vivenciaron una experiencia de estigma por haber sido dejadas por el marido. Pero el entrevistador no fue directamente a este asunto, él intentó conversar sobre la experiencia de ser dejada como un todo, de forma más general, facilitando la emergencia de la descripción del fenómeno como un todo.

Solamente en el momento del análisis en que "sale del paréntesis", el investigador enfoca específicamente el estigma de ser dejada por el marido. O sea, en este momento, el investigador re-asume su mundanidad, analizando el estigma que él sospechaba haber en esta experiencia de las mujeres dejadas por sus maridos. Pero este es también el momento en que el investigador refleja sobre todo el contenido emergente, incluyendo todo lo que él piensa sobre lo que ocurre en la entrevista, articulando, entonces, con su propia experiencia y conocimiento. Se trata del rato en que el pesquisidor refleja sobre lo que él aprendió con el sujeto-colaborador.

A partir de la delimitación de los movimientos, organizamos un cuadro de análisis exponiendo la descripción de cada uno de ellos para, en secuencia, alimentarnos su comprensión con una versión comprensiva y psicológica de los mismos. A esta comprensión podemos llamar "versión de sentido" (apropiándose del recurso clínico propuesto por Amatuzzi, 2000), pues se trata de una versión decurrente de nuestra escucha sobre el fenómeno. Este sería el momento de análisis del significado emergente del movimiento (Moreira, 2004, p. 454). Y, finalmente, articulamos tal comprensión a reflexiones que remiten nuestras hipótesis y nuestro referencial teórico de soporte. Sería el momento de alejamiento reflexivo, cuando estaremos, por lo tanto, saliendo de los paréntesis.

Veamos un ejemplo de la división en movimientos de una entrevista:

I1: Estoy investigando sobre el rompimiento de relaciones amorosas y me gustaría su ayuda para comprender este tema...

E: El que pueda ayudarle.../M1/

I2: ¿Cómo fue para ti esa vivencia de separación?

$\mathrm{E}$ : Todo fue tan rápido, que solamente después de algunos días, semanas, fui a sentir este aprieto, ¿sabes?/M2/

Mi vida cambió pronto porque yo vivía dependiendo de él, ¿sabe?/M3/

Ahora, estoy en la casa de mi madre, pero estoy buscando un trabajo [respira a fondo, mira la ventana en silencio]/M4/

Yo sufro mucho... nunca pensé que eso fuera a ocurrir en mi vida. /M5/ 
Tabla 1: Análisis descriptivo de diez intervenciones realizadas.

MODELO DE LA

INTERVENCIÓN

I(1): Estoy investigando sobre rompimiento de relaciones amorosas y me gustaría su ayuda para comprender este tema....

I(2): ¿Como fue para ti esta separación?

I(3): Él volvía para que usted le sirviere comida y ropas limpias...

I(4): ¿Así cómo?

I(5): Usted está diciéndome que no te gustaba tener relaciones sexuales con él, ¿es eso?

I(6): Entonces...

I(7): ¿Y cómo Usted se sintió cuando él rompió el matrimonio?

I(8): Tenía entendido que Usted no querría verlo.

I(9): Parece que Usted está acordándose de cuando ustedes se casaron y ahora habla de que se preocupa por la vejez de él...

I(10): Debe haber sido difícil para Usted esa separación... es como si tuviese que reempezar..

TIPO DE LA INTERVENCIÓN Y MOMENTO DIALOGAL

Se trata del rapport inicial. Permite implicar al sujeto-colaborador en la comprensión profunda del problema

Es la pregunta disparadora. Puesta de forma abierta, clara y vuelta para la perspectiva del sujeto.

Es una puntuación de elucidación.

Es una pregunta que visa pesquisar con más detalles sobre elementos no comprendidos.

Es una pregunta explicativa.

Un eco.

Aquí, el retorno a la perspectiva vivencial del fenómeno estudiado.

Una confrontación. Momento de ampliar la conciencia sobre el movimiento temporal de las representaciones.

Una reiteración

Una reflexión de sentimientos
EFECTO DE LA INTERVENCIÓN
Se espera que el sujeto sienta la importancia que su vivido tiene para la comprensión del fenómeno, valorizando su singularidad y tornándose responsable, también, por la colecta.

Se espera que el sujeto se sienta motivado a rescatar su modo propio de comprensión de su vivencia y construya un flujo que aún no fue relatado y/o elaborado.

Se espera que el sujeto-colaborador confirme o no la comprensión del investigador.

Además de procurar engendrar una aclaración, procura mantener el flujo discursivo. Tales aclaraciones visan la minuciosidad de la descripción y el poner en palabras lo que está expreso en las entrelíneas.

Un último recurso para tornar presente el "ver y oír" fenomenológico. El clima dialogal podrá facilitar ese nivel de complicidad en la entrevista, respetando la abertura que el otro señaliza.

Visa la manutención del flujo discursivo

Espera que el sujeto se apropie de los contenidos emocionales articulados a la narrativa.

Remete el sujeto al paradoja sus representaciones. Tanto actualiza como posibilita la ampliación de su conciencia.

Procura integrar diferentes perspectivas temporales y espaciales de la vivencia descrita. Amplía la conciencia del sujeto y facilita una aproximación con el núcleo del vivido

Como postura empática favorece el clima dialogal y también actualiza el vivido, afirmándolo.
Yo no creía que un matrimonio pudiera terminar así... porque yo me casé para construir familia, cuidar de la casa y del marido... entonces, que yo sepa que él salía por ahí... son cosas de hombre... pero mantenía la familia, ¿sí?/M6/

... ahí, así, de pronto llegar y decir que se marchaba... sin más ni menos... fue horrible, porque yo llegué a la casa - yo había llevado J. para el médico; ahí él estaba en la puerta con una maleta y dejando unos bolsos en la camioneta... ahí él me dijo que iba a viajar. “¿Dónde vas?” pregunté, ¿sí? “¡Me voy, mujer!” entonces empecé a llorar y preguntar para dónde iba, y por qué él estaba haciendo esto y él sólo decía que iba a salir y que no iba a decir para dónde. Dijo que yo me quedase con la casa, que él se iba a salir./M7/
Fue una cosa horrible, porque yo no sabía lo que yo iba a hacer... Aún hoy nadie más supo de él, nadie más le vio, él... él no tenía más familia, ¿sí? /M8/

Vivía en la alquería y ahí vine a vivir con mi madre, porque la alquería era lejana y estaba el bebé... ahí mi hermano cuida de allá, ¿sí?... pero yo quiero vender y comprar una casa en la ciudad./M9/

I3: ¿La situación de la alquería te preocupa?

E: Sí, ¿vale? No puedo cuidar de allá, ¿sí? que estoy con este bebé pequeño y ahí yo vendo, compro una casita y guardo lo que sobrar/M10/

En la Tabla 2 abajo esquematizamos el conjunto de análisis de cada movimiento identificado. 
Tabla 2: Análisis descriptivo de los movimientos

\section{MOVIMIENTOS}

DESCRIPCIÓN VERSIÓN DE SENTIDO
SALIENDO DEL PARÉNTESIS
D: Estoy investigando sobre el rompimiento de relaciones amorosas y me gustaría su ayuda para comprender este tema...

E: En qué puedo ayudarle...

D: ¿Cómo fue para ti esa vivencia de separación?

E: Todo fue tan rápido, que solamente después de algunos días, semanas, fue que fui a sentir este aprieto, ¿sabes?

Mi vida cambió pronto porque yo vivía dependiendo de él, ¿sabe?

Ahora, estoy en la casa de mi madre, pero estoy buscando un trabajo [respira profundo, mira la ventana en silencio]

Yo sufro mucho... nunca pensé que eso fuera, ocurrir en mi vida.

Yo no creía que un matrimonio pudiera terminar así... porque yo me casé para construir familia, cuidar de casa y del marido... entonces, que sepa que él salía por ahí... es cosa de hombre... pero mantenía la familia, ¿sí?
Se pone disponible.

Buena relación al rapport inicial.

Relata que solamente después de dos días sintió la pérdida.

Relata que su vida ha cambiado pues era dependiente del marido.

Describe sobre su condición social e individual. Su lenguaje corporal sugiere un aire de desolación.

Se refiere a sufrir. En su perspectiva, este sufrir no era esperado.

Afirma no creer que el matrimonio podría acabar porque no fuera eso que siempre pensó. Mantendría la relación, aun con las relaciones extra-conyugales del marido. En su modo de ver y pensar, la infidelidad forma parte del universo masculino y de importante en la mantención de la familia.
Fue un hecho que le costó "digerir", o sea, demoró, según su perspectiva temporal, para ser elaborado.

Aparente ella sintiéndose desorientada, sin la referencia de vivencia que significaba para sí como mujer casada.

Parece sentirse sin senda buscando perspectivas. Parece intentar amenizar su condición de vuelta para casa de su madre.

Es como si sintiera decepción frente a todo eso.

Parece decepcionada frente a sus expectativas sobre el matrimonio. Al mismo tiempo que se pone en la posición de conformidad, parece sentirse perdida con la no concretización de sus ideas sobre el matrimonio.
Fueron indicados los objetivos de la entrevista claramente, de tal forma que el sujeto-colaborador pudo exponer su aceptación de la invitación y compareciendo a la entrevista. La forma en que esto ocurrió parece que la hizo sentir libre para colaborar y hablar de esta temática conmigo, a pesar de la vergüenza que siente del hecho.

La vivencia temporal del rompimiento fue diferente del tiempo real del hecho, revelando, posiblemente, resistencias en el proceso de elaboración. Ello posiblemente se relaciona con el estigma, es decir, con el hecho de ella a vivir esto como algo despreciativo.

Es una de las primeras reacciones que la literatura apunta como consecuente al rompimiento: el choque que desorienta y rompe la estructura de los ideales y perspectivas ya definidas.

Tratase de un rompimiento en la estructuración en términos de encontrar un nuevo papel social para ser encuadrada, visto que era dependiente del marido. Posiblemente se siente inferior por tener que cuidarse sola, que es una referencia al estigma vivido

Esa decepción parece recurrir de la propia necesidad de re-estructurar la pérdida y de reencontrarse en la red social, asumiendo un nuevo papel. En la verdad, esa situación no era lo que esperaba, es algo malo, pues tiene connotación estigmatizadora.

En el contexto en que vive, el matrimonio es una institución valorizada y las mujeres, desde temprano, crían perspectivas sobre su momento de "formar familia”. De ahí ser comprensible su decepción: ese ideal se deshizo. No tener una familia sería, entonces, algo para sentir vergüenza (elemento social cargado de estigma). 
... ahí, así, de pronto llegar y decir que se marchaba... sin más ni menos... fue horrible, porque yo llegué a casa, pues yo había llevado J. para el médico; ahí él estaba en la puerta con una maleta y dejando unos bolsos en la camioneta... ahí él me dijo que iba a viajar.

“¿Dónde vas?” pregunté, ¿sí? "¡Voy a marcharme, mujer!" Entonces yo empecé a llorar y preguntar para dónde iba, y porque él estaba haciendo esto y él sólo decía que iba a marcharse y que no iba a decir para dónde. Dijo que yo me quedase con la casa, que él se iba a salir.

Fue una cosa horrible, porque yo no sabía lo que yo iba a hacer... Aún hoy nadie más supo de él, nadie más le vio, él... él no tenía más familia, ¿sí?

Vivía en la alquería y ahí vine a vivir con mi madre, porque la alquería era lejana y estaba el bebé... mi hermano cuida de allá, ¿sí?... pero quiero vender y comprar una casa en la ciudad.

D: ¿La situación de la alquería te preocupa?

E: sí, ¿vale? No puedo cuidar de allá, ¿sí? que estoy con este bebé pequeño y ahí vendo, compro una casita y guardo lo que sobra.
Relata el día en que fue dejada: puso las cosas en la camioneta y dijo que iba a salir. Relata haber llorado.

Relata que no sabía qué hacer y que no encontró más al exmarido.

Dijo que vivía en la alquería y con la separación vino a morar con su madre. Cuenta perspectivas para mudanza de vida, deshaciéndose de bienes materiales.
Dice que se siente preocupada con la situación de la alquería y del bebé.
Se sintió desesperada al verse dejada sin motivos claros. En su descripción existe un clamor de apego, de incredulidad.

Se sentía sin perspectivas, desorientada.

Sin norte, sola, vuelve para la casa de su madre. En realidad, parece existir un mirar pragmático sobre lo que hacer, a partir de ahora.
Describe los elementos que, en su modo de vivir, fueron dibujo en su experiencia de rompimiento. Aquí hace referencias sobre su papel de esposa en aquél contexto: cuidar de la salud de su hijo y compartir las decisiones con su marido. Desafortunada por la decisión del cónyuge, se vio sin perspectivas y eso parece causarle desespero. Aún es patente su pasividad frente al hecho, que simplemente aceptó. Se siente disminuida, incapaz por no poder mantener su marido consigo.

En esta situación, se vio sin rumbo, no encontrando motivos para esta decisión inesperada de su marido. Tal vez por eso su discurso sea tan repetitivo, como si quisiese buscar respuestas para sí.

Frente a lo que tiene, empieza a vislumbrar perspectivas para su vida: mantener el apoyo de su madre para auxiliar en los cuidados del bebé y vender los bienes para adquirir otros. Esa operacionalización empieza a dar sentido a su vida. Ella parece buscar la re -estructuración de sí en las operaciones externas. Su relato es lineal, pero la construcción de esa nueva perspectiva tomó tiempo. Fenomenológicamente, podemos decir que se trata de una dialéctica sobre los contornos de la experiencia vivida, conduciendo al polo de la re-elaboración, pero sin generar una síntesis, lo que hace que su experiencia pueda ser reelaborada a partir de infinitos flujos de sentido. Esa es una condición de valor mundano, como sugiere Merleau-Ponty.

Parece preocupada con el bebé, necesita apoyo.
Enfoca la nueva estructuración de su vida en el cuidado del hijo y eso la mueve.

\section{Conclusiones}

Buscamos la comprensión de la vivencia que traspasa por un contexto histórico, que la caracteriza en sus idiosincrasias. Buscamos adecuar, metodológicamente, la investigación, como una comprensión de un fenómeno vivencial concreto, presente en el mundo, como dado de la realidad y evidenciado en el discurso cotidiano de las personas. Intentamos privilegiar las idiosincrasias y las ambigüedades inherentes al estatus del sujeto productor de flujos de sentido, ante un envolvimiento existencial constituido en torno de hechos multifacéticos de las experiencias y de la polisemia a ellos inherentes. Por lo tanto, la comunicación de los resultados visa a crear presencia, en detrimento de 
establecer relaciones de causa y efecto, parte y todo, antecedente y consecuente. Pretendemos, al contrario, defender la idea de tornar el objeto presencia en la conciencia de quien está siendo comunicado y comunicando.

Si por un lado la entrevista fenomenológica, fundamentada en la filosofía de Merleau-Ponty, favorece el "tornar presente" las variadas dimensiones de la experiencia vivida, ella puede, también, favorecer el engendramiento de motivación para la mudanza de conducta (y del proyecto existencial) ante el contenido descrito, teniéndose en cuenta la facilitación de la ampliación de la consciencia del sujeto colaborador decurrente de las intervenciones de la escucha activa. De esta manera, esta modalidad de entrevista y su metodología de análisis parecen ser viables y útiles para la encuesta clínica, que busca comprender la intimidad humana. Esta permite comprender el desarrollo temporal de las representaciones de la vivencia, lo que facilitaría el análisis de la elaboración de la experiencia vivida, que el sujeto puede desdoblar. Por eso, las intervenciones fenomenológicas son de suma importancia; porque tales representaciones, en el rato en que son rescatadas por la memoria, igualmente se reflejarían en circunstancias de sufrimiento psíquico (Robinson \& Clore, 2002). Pero, aquí, debemos mantenernos circunspectos, pues existe la necesidad de investigaciones que mejor comprendan esa dinámica entre la vivencia (pre-reflexiva), sus representaciones (reflexivas) y la obnubilación que pueden sufrir, en el contexto de la desorganización psicológica, que estarán sobre la medición de la memoria y bajo la moderación de las intervenciones del investigador, en el contexto de la pesquisa fenomenológica.

Desde el punto de vista de los límites identificamos la necesidad de la plena participación del investigador en todas las fases de la pesquisa y la necesidad de un entrenamiento de técnicas de facilitación del discurso, resguardando los elementos éticos envueltos en este trabajo, a fin de que éste no se confunda con consejos, ni con psicoterapia. Otro límite se refiere a la influencia del efecto de inhibición de la descripción o de (ante la expectativa social) que pueden favorecer la distorsión de datos, cuando es realizada en grupo. El ejercicio de las intervenciones fenomenológicas se configura como una importante dimensión de la colecta de datos, pues ella favorece la múltiple escucha del investigador y la reducción fenomenológica no prescinde de esa múltiple escucha, que debe estar presente en el proceso global de la investigación.

La múltiple escucha podrá presentificar la implicación del investigador, es decir, su "embotellamiento" en el campo intersubjetivo facilitado; sea como fuente de la tensión de polaridades investigador/sujeto colaborador, sea como fuente de la dimensión intrasubjetiva que es afectada por el sujeto que describe el propio vivido (y que también puede afectar al sujeto si no se ha puesto entre paréntesis, en el momento de envolvimiento existencial). Es válido destacar que son de estos contenidos de la tensión engendrada entre los protagonistas en la colecta - por donde el fenómeno de la intersubjetividad traspasa y forma parte de las diversas dimensiones vivenciales de la investigación, para allá de la problemática, que el investigador encontrará su versión de sentido, actualizada por sus hipótesis y teorías.

Aun así, un límite puesto por el sujeto-colaborador puede ser la dificultad de generar insight y de aproximarse de los contenidos vivenciales. Tal dificultad puede no solamente frenar la facilitación del flujo de producción de sentidos, sino también acarrear en la pura descripción de hechos, en el alejamiento de la implicación del sujeto ante la vivencia y exigir más directividad por parte del investigador; que, por su vez, puede minar el sentido de la falla auténtica. Delante de eso, aseveramos la importancia del significado sobre el contenido en sí. Pues eso, creemos que la saturación prevista en otros métodos fenomenológicos no sería visada en esta perspectiva, entendemos que la investigación crítica merleau-pontyana debe favorecer una comprensión "abierta" del fenómeno, al revés de una síntesis o de la búsqueda de la esencia. Entendemos también la necesidad de una amplia constitución del grupo de sujetos-colaboradores, pues así tendríamos mayores posibilidades de una mayor variabilidad de significados, $y$, por consecuencia, una gran profundidad de la comprensión del fenómeno investigado, mismo que, aquí, otro límite sea vislumbrado: el de que la descripción nunca es completa.

\section{Referencias}

Abbagnano, N. (1998). Dicionário de Filosofia. São Paulo: Martins Fontes.

Amatuzzi, M. (1989). O resgate da fala autêntica. Campinas: Papirus.

Amatuzzi, M. M. (1994). Relatos de acontecimento de vida: Uma via de acesso a identidade pessoal. Revista Psicologia: reflexão e crítica,7, 93-123.

Amatuzzi, M. M. (1996). Apontamentos acerca da pesquisa fenomenológica. Estudos de Psicologia, 3, 5-10.

Amatuzzi, M. M. (2000). Por uma psicologia humana. Campinas: Alínea.

Benjamin, A. (2002). Entrevista de ajuda. São Paulo: Martins Fontes.

Coelho Jr.,N. \& Carmo, P.S. (1991). Merleau-Ponty : Filosofia como corpo e existência. São Paulo: Escuta.

Forghieri, Y. C. (1989). Contribuição da fenomenologia para o estudo das vivências. Rev. Bras. de Pesq. em Psicologia, 2, 7-20.

Forghieri, Y. C. (1993). Pesquisa fenomenológica. São Paulo: Pioneira

Guedes, D. \& Andrade, A. (1999, maio). Psicoterapia Fenomenológico Existencial Centrada na Pessoa: a atenção e conduta do psicoterapeuta - proposta de introdução do campo da clínica. Trabalho apresentado no VIII Encontro da Abordagem Centrada na Pessoa. Maragogi-AL.

Guedes, D. (2002). A vivência de ser deixada em Tianguá-CE: Um estudo fenomenológicosobre o rompimento unilateral de relações amororas. Dissertação de Mestrado não publicada, Mestrado em Psicologia, Universidade de Fortaleza.

Merleau-Ponty, M. [1945 (1994)]. Fenomenologia da percepção. São Paulo: Martins Fontes.

Merleau-Ponty, M. (1974). La fenomenología y las ciencias del hombre. Nova: Buenos Aires. 
Moreira, V. (1998). Técnicas de intervención fenomenológica en psicoterapia. En II Congreso Iberoamericano de Psicología (Org.), $C D$ da Sección Psicología Clínica y Salud Mental. Madrid.

Moreira, V. (2001). Más allá de la personna: Hacia una psicoterapía fenomenológica mundana. USACH: Santiago.

Moreira, V. (2004). O método fenomenológico de Merleau-Ponty como ferramenta crítica na pesquisa em psicopatologia. Psicologia: Reflexão e crítica, 13, 447-456.
Moreira, V.; Saboia, A.; Beco, L. \& Soares, S. (1995). Psicología fenomenológico-existencial: Aspectos teóricos de la práctica clínica con base en las competencias. Psykhe, 4, 121-129.

Robinson, M.D. \& Clore, G.L. (2002). Episodic and semantic knowledge in emotional self-report: Evidence for two judgement processes. Journal of personality and social psychology, 83, 198-215.

Rogers. C. R. \& Kinget, J. (1977). Psicoterapia e relações humanas. São Paulo: Martins Fontes. 


\title{
Directorio Sociedad Chilena de Psicología Clínica 2009 - 2010
}

\author{
Caterina Manzo García \\ Presidenta \\ Susana Ifland Levin \\ Vicepresidenta \\ Jade Ortiz Barrera \\ Tesorera
}

Walter Kühne Covarrubias

Secretario

Directores:

Italo Garcia Jará

Felipe Lecannelier Acevedo

Mónica López Hernando

Irene Salvo Agoglia

Jaime Silva Concha

Pablo Vera Villarroel

Ricardo Matte Pérez 492, Providencia.

Santiago, CHILE.

Fono: (56)(2) 2090286

Fax: (56)(2) 2698328

E-mail: sochpscl@entelchile.net

www.sociedadchilenadepsicologiaclinica.cl 